\title{
Institucionalidad y problemáticas de la Comunidad Andina de Naciones
}

\author{
Fecha de recepción:01/03/2010 - Aprobación:05/04/2010
}

\section{Ángela Gómez Jutinico}

\section{Resumen}

Este articulo hace un análisis de los cambios institucionales que ha sufrido la Comunidad Andina de Naciones (CAN) desde su creación en 1969, los cuales han significado varias reformas estructurales al interior de los órganos que la componen, explicando que este fenómeno a su vez ha ocasionado una crisis de institucionalidad en el organismo regional.

Adicional al estudio de la problemática de institucionalidad de la CAN, también se identifican y analizan otras problemáticas como son el interés de conflicto entre los Estados miembros y la heterogeneidad en el desarrollo económico de las naciones que hacen parte del proceso de integración regional.

Por último el artículo destaca algunas diferencias relevantes entre el proceso de integración andino y la Unión Europea, centrando su análisis en las asimetrías en el nivel de vida de los habitantes y las diferencias institucionales.

\section{Abstract}

This paper analyzes the institutional changes that have taken place in the Andean Community of Nations since its creation in 1969, which has resulted into several structural changes within its main organs. This article also explains that this phenomenon has led to a crisis of institutions within the regional organization.

Besides the study of the problem of the institutions, other issues are also identified and analyzed, such as the conflict of interest between member states and the heterogeneity of the economic development of nations that are part of the regional integration process.

Finally, the paper highlights some relevant differences between the Andean integration process and the European Union, by focusing its analysis on the asymmetries in the standard of living of the inhabitants and the institutional differences.

\section{Palabras clave}

Comunidad Andina, problemáticas, instituciones, asimetrías, Unión Europea.

\section{Key words}

Andean Community, Problematics, Institutions, Asymmetries, European Union.

\section{Introducción}

En el año de 1969, un grupo de naciones suramericanas suscribó el Pacto Andino, acuerdo que tenía como propósito primario el estable- cimiento, en el lapso de diez años, de una zona de libre comercio entre los países signatarios. Sin embargo, en un periodo de tres décadas, los países integrantes de ese pacto, luego de un 
largo proceso de toma de decisiones políticas e iniciativas técnicas, comerciales y sociales, se constituyeron en la Comunidad Andina de Naciones (CAN). Desde su nacimiento una de las principales características es su institucionalidad, pues la creación de órganos que ejerzan funciones supranacionales desde el punto de vista Legislativo, Ejecutivo, Judicial y de consulta son relevantes en la dinámica de este proceso de integración.

A pesar de los intentos por cumplir con los objetivos del Acuerdo de Cartagena mediante su estructura institucional, la CAN presenta problemas al interior de sus órganos que debilitan esta tarea, como su pérdida de legitimidad, la limitada funcionalidad y la falta de efectividad mediante la coerción de sus órganos, en el cumplimiento de los objetivos.

No obstante lo anterior, la CAN no solo enfrenta la problemática derivada de su institucionalidad, también presenta dificultades de diferente orden que impiden la realización de sus objetivos, como los enfrentamientos políticos entre los dirigentes de los países miembros que ocasionan conflicto y tensión en la zona. Por otra parte, las economías de los miembros del proceso de integración

\section{Reseñas de autores \\ Angela Gómez Jutinico}

(Politécnico Grancolombiano)

anggomez@poligran.edu.co

Docente universitaria, directora del Departamento de Derecho de la Institución Universitaria Politécnico Grancolombiano, abogada de la Universidad Libre de Colombia, Especialista en Derecho Comercial de la Pontificia Universidad Javeriana, candidata a Máster en Derecho Económico de la Pontificia Universidad Javeriana.

El presente artículo fue obtenido en el desarrollo de un proyecto de investigación que se encuentra adscrito a la línea de investigación en derecho económico del Programa de Derecho del Politécnico Grancolombiano. siguen siendo muy heterogéneas, a pesar de los esfuerzos que se han venido implementando en América Latina por medio de varios organismos entre los que se encuentra la ALALC (Asociación Latinoamericana de Libre Comercio), la Aladi (Asociación Latinoamericana de Integración) y el BID (Banco Interamericano de Desarrollo), entre otros.

\section{Análisis de las instituciones de la CAN}

Desde la creación de la Comunidad Andina de Naciones -en sus inicios Pacto Andinopor medio del Acuerdo de Cartagena en 1969, este organismo de integración económica subregional ha aumentado de instituciones y órganos en número, tamaño y vínculos, además de suprimido o modificado otros tantos. Así, en sus inicios el Pacto Andino estaba conformado por dos grandes instituciones de decisión (la Comisión y la Junta), un órgano consultivo (el Comité Asesor Económico y Social) y dos entidades de soporte financiero y económico (Corporación Andina de Fomento, CAF, y el Fondo Andino de Reserva, FAR).

En la actualidad, el conjunto de instituciones de la Comunidad Andina de Naciones (CAN) se encuentran integradas en el Sistema Andino de Integración (SAI), cuya finalidad es

permitir la coordinación efectiva entre sí para profundizar la integración subregional andina, promover su proyección externa y robustecer las acciones relacionadas con el proceso de integración

(http://www.comunidadandina.org/ sai/que.htm).

Dichas instituciones se rigen por el Acuerdo de Cartagena, que les dio origen, 
por sus respectivos tratados constitutivos y los protocolos modificatorios, como son:

a. Órganos de dirección y decisión

- Consejo Presidencial

- Consejo Andino de Ministros de Relaciones Exteriores

- Comisión de la Comunidad Andina.

b. Como órganos que detentan las tres ramas del poder

- Secretaría General (Ejecutivo)

- Parlamento Andino (Legislativo)

- Tribunal Andino de Justicia (Jurisdiccional).

c. Instituciones consultivas

- Consejo Consultivo Empresarial

- Consejo Consultivo Laboral

- Consejo Consultivo de los Pueblos Indígenas.

d. Cómo instituciones financieras

- Corporación Andina de Fomento (CAF)

- Fondo Latinoamericano de Reservas (FER).

e. Instancias sociales

- Convenio Hipólito Unanue

- Convenio Simón Rodríguez

- Universidad Andina Simón Bolivar.

\subsection{Historia institucional}

Antes de iniciar con el análisis de las funciones y atribuciones de cada uno de los órganos e instituciones que se enuncian anteriormente, tal y como están concebidos en la actualidad, resulta relevante realizar un breve recorrido histórico acerca del desarrollo institucional que ha tenido la Comunidad Andina desde
1969 (año de su creación) hasta 1996 con el establecimiento del Sistema Andino de Integración (SAI).

La primera etapa vivida por la CAN es la comprendida entre el año de 1969 a 1979, en el texto codificado del Acuerdo de Cartagena de 1969. La Comisión era el máximo órgano, constituido por un representante plenipotenciario y uno alterno de cada uno de los países miembros. Su función principal era la de legislar, y sus atribuciones, entre otras, eran las siguientes:

- Trazar la política general y adoptar las medidas necesarias para alcanzar los objetivos del Acuerdo

- Aprobar las normas indispensables para la coordinación de las políticas de cada Estado parte

- Designar y remover los miembros de la Junta

- Impartir instrucciones a la Junta

- Aprobar o no las propuestas presentadas por la Junta

- Velar por el cumplimiento del Acuerdo y del Tratado de Montevideo

- Proponer modificaciones al Acuerdo frente a los Estados miembros.

Por su parte, la Junta era un órgano técnico, que actuaba únicamente en función de los intereses de la subregión. Integrada por tres miembros de nacionalidad latinoamericana, era responsable ante la Comisión. Se manifestaba mediante resoluciones, tomadas por unanimidad. Entre sus atribuciones, se encontraban:

- Velar por el cumplimiento del Acuerdo en cumplimiento de las disposiciones de la Comisión

- Cumplir con los mandatos de la Comisión
La primera etapa vivida por la CAN es la comprendida entre el año de 1969 a 1979 , en el texto codificado del Acuerdo de Cartagena de 1969. El Pacto Andino contaba con una organización institucional simple, conformada por dos instituciones principales, la Comisión y la Junta, un órgano auxiliar, el Comité Asesor Económico y Social, y dos entidades de apoyo financiero, la Corporación Andina de Fomento y el Fondo Andino de Reservas. 
- Formular propuestas a la Comisión, referentes a la aceleración del proceso integracionista

- Participar eventualmente en las reuniones de la Comisión

- Efectuar estudios técnicos

- Ejercer funciones de secretario permanente y mantener las relaciones con los gobiernos de los países miembros.

Finalmente, el Comité Asesor Económico y Social estaba constituido por un representante de los países miembros, designados por el Ejecutivo correspondiente. Su principal función era servir de contacto entre los gobiernos y la Junta, al mismo tiempo que fungía de órgano consultor de esta última.

La segunda de las etapas es la comprendida entre los años 1979 a 1996, época en la que se presentaron grandes cambios en la organización en el nivel institucional del Pacto Andino, más conocido por ese entonces como Grupo Andino (GRAN).

Además de la Comisión y la Junta, se sumaron dos nuevos órganos principales, el Parlamento Andino y el Tribunal Andino de Justicia. Estos se establecen definitivamente en la CAN en 1984, coincidente con un periodo de mayor actividad y con el establecimiento definitivo de la democracia en la subregión. Tales órganos se rigen por los tratados constitutivos que les dieron lugar.

El Parlamento Andino se instauró como un órgano deliberante, cuyos miembros debían ser elegidos por sufragio directo y universal (cinco representantes principales, cada uno con dos suplentes). Sus atribuciones generales son las siguientes:

- Examinar los avances en el proceso de integración mediante reportes anuales $\mathrm{u}$ otro tipo de información, fun- ción que era meramente facultativa del órgano

- Mantener relaciones con los parlamentos de los países miembros y de otros países

- Proponer medidas y sugerencias para armonizar la legislación de los países miembros.

Por su parte, el Tribunal Andino se creó como órgano judicial para garantizar la obediencia estricta de las obligaciones emanadas del Acuerdo y sus tratados adicionales. Sus decisiones tenían fuerza de ley andina, que prevalecía sobre la nacional. Estaba integrado por un representante de cada país, con sus respectivos suplentes. Entre sus funciones principales (jurisdiccionales y de supervisión) se encuentran:

- Encarnar en poder judicial

- Declarar nulas las decisiones de la Comisión

- Iniciar la acción de cumplimiento contra los Estados parte

- Interpretar la ley andina.

Además de la creación de estos dos órganos, durante este periodo se suprimió el antiguo Comité Asesor, y se dio vida a dos consejos consultores distintos: el Consejo Consultor Empresarial y el Consejo Consultor Laboral, ambos integrados por delegados de alto nivel elegidos por las organizaciones más representativas de los sectores empresarial y laboral de cada uno de los países miembros.

Por último se crearon el Consejo Presidencial Andino y el Consejo de Ministros de Relaciones Exteriores, órganos que aunque no estaban incluidos en el 
Acuerdo (situación que no cambió hasta 1996), sí actuaron desde sus inicios como instituciones "de buena fe" (Bustamante, 2004) en el proceso integracionista.

El Consejo Presidencial estaba constituido por los presidentes de los países miembros, y su función principal era dar las pautas generales para el proceso. Igual labor tenía el Consejo de Ministros, quienes debían reunirse para dar los lineamientos generales sobre el mismo tema.

Ante esta nueva perspectiva, la Junta no sufrió mayores modificaciones, pero la Comisión empezó a verse un poco relegada de las funciones que en un principio ostentaba exclusivamente, a la vez que adquiría nuevas atribuciones, cuales eran:

- Aprobar o no las propuestas de los países miembros

- Evaluar trienalmente el proceso de integración y modificar eventualmente los plazos previstos y las normas

- Mantener relaciones con los nuevos órganos de decisión

- Representar el Acuerdo en asuntos de interés común.

Y la última de las etapas es la vivida desde 1996, pues a partir de esta fecha con el Protocolo Trujillo, se puso en práctica el Sistema Andino de Integración (SAI), que además de los Estados miembros, está constituido por todos aquellos órganos e instituciones que hoy en día existen, y que se enumeraron al inicio de este trabajo. La diferencia de esta nueva organización y la de los años anteriores, además del evidente crecimiento en cantidad de instituciones, es que entre estas no se decía expresamente cuáles eran principales y cuáles eran auxiliares. Sin embargo durante los años se asumió que todas aquellas a las cuales la norma no les había asignado funciones específicas eran de carácter auxiliar.

El SAI dotó de legalidad y estructura institucional a todos los órganos e instituciones, aunque no estuvieran antes incluidas en el Acuerdo. Se dio paso así a la nueva estructura de la Comunidad Andina de Naciones (como se empezó a llamar a partir de ese momento), cuyos órganos se analizan a continuación:

\section{2Órganos e instituciones de la Can en la actualidad}

En la actualidad la Comunidad Andina de Naciones está compuesta por los siguientes órganos cuyas funciones más importantes se describen a continuación:

\section{Consejo Presidencial Andino}

Es el máximo órgano del SAI, cuya principal labor es dirigir el proceso de integración subregional andina, estableciendo de tal suerte los lineamientos generales para llevar a cabo dicho proceso mediante directrices y mandatos. Está integrado por los jefes de Estado de los Estados parte (Colombia, Bolivia, Perú y Ecuador).

Sus funciones principales son:

- Definir la política de integración y su proyección externa, mediante seguimiento y evaluación de sus resultados

- Coordinar la labor de los diferentes órganos e instituciones del SAI, mediante la orientación e impulso de sus acciones relativas a la integración, y revisar y pronunciarse acerca de sus iniciativas, informes y recomendaciones.

\section{Consejo Andino de Ministros de Relaciones Exteriores}

Es el órgano de dirección política, cuya función principal es verificar el cumplimiento 
de los objetivos integracionistas y formular $\mathrm{y}$ ejecutar la política exterior de la CAN, materia en la cual tiene competencia legislativa, mediante declaraciones y decisiones adoptadas por consenso (las Decisiones hacen parte del ordenamiento jurídico de la CAN). Está presidido por el ministro de Relaciones Exteriores del país que tiene la presidencia del Consejo Presidencial, e integrado por los cancilleres de los Estados parte.

Sus funciones principales son:

- Formular la política exterior de los Estados parte en función de los intereses regionales, mediante la orientación y coordinación de las acciones externas de todos los órganos e instituciones del SAI

- Cumplir con las directrices del Consejo Presidencial y velar por el cumplimiento de aquellas dirigidas a los otros órganos andinos

- Representar a la CAN en asuntos y actos de interés común.

- Formular, ejecutar y evaluar, junto a la Comisión, la política general de integración subregional

- Tomar las medidas necesarias para el cumplimiento de los objetivos del Acuerdo.

\section{Comisión de la Comunidad Andina}

Deja de ser el máximo órgano de la Comunidad, y pasa a ser el órgano encargado de formular, ejecutar y evaluar la política de integración subregional andina en materia de comercio e inversiones. Comparte las funciones del Consejo de Ministros de Relaciones Exteriores en cuanto a la adopción de las medidas necesarias para el cumplimiento de los objetivos integracionistas, el cumplimiento de las directrices del Consejo
Presidencial y la labor de coordinación de los países miembros en foros y negociaciones internacionales. De igual modo, aprueba o no las propuestas que sometan a su consideración los Estados miembros, individual o colectivamente, y la Secretaría General.

\section{Secretaría General}

En sus inicios, la Junta es el órgano ejecutivo del SAI, cuya función principal es administrar el proceso de integración subregional. Está dirigida por un secretario general elegido por consenso por el Consejo de Ministros de Relaciones Exteriores. Aunque se prevé que pueda actuar únicamente en función de los intereses comunitarios, en la actualidad ha perdido su función de iniciativa. Tiene principalmente función propositiva, toda vez que puede formular propuestas de decisión ante los órganos de decisión y dirección. Entre otras de sus funciones están:

- Atender a los encargos del Consejo de Ministros de Relaciones Exteriores y de la Comisión

- Decidir sobre los asuntos puestos a su conocimiento

- Velar por el cumplimiento de los compromisos adquiridos por la CAN.

- Mantener vínculos con los países miembros, con los demás órganos e instituciones del SAI y con los órganos ejecutivos de otras organizaciones regionales de integración y cooperación

- Realizar estudios técnicos encomendados por los órganos del SAI y otros que considere necesarios.

\section{Parlamento Andino}

Es el órgano deliberante del SAI, el cual representa a todos los pueblos de la CAN. 
Sus representantes son elegidos por los congresos nacionales de cada uno de los estados miembros, aunque en virtud del Protocolo Adicional modificatorio del Tratado Constitutivo, la elección de los representantes se hará por voto directo y universal. Sin embargo, a pesar de las funciones que le son encomendadas, el Parlamento sigue siendo un órgano meramente burocrático, que poco o nada puede contribuir al proceso de integración subregional, toda vez que su papel es sobre todo de promotor e impulsor. Carece de vínculos reales con los otros órganos del SAI, por lo que su labor resulta ser independiente.

Entre sus funciones principales se encuentran:

- Participa en la generación normativa del proceso, mediante sugerencias a los órganos de dirección del SAI. (www.comunidadandina.org/normativa)

- Promueve la armonización de las legislaciones de los Estados miembros.

- Fomenta las labores de cooperación y coordinación entre los parlamentos de los Estados miembros y de terceros países.

- Formula recomendaciones sobre los proyectos de presupuesto anual de los órganos e instituciones del SAI, que se constituyen con contribuciones directas de los países miembros.

\section{Tribunal Andino de Justicia}

Es el órgano jurisdiccional del SAI, integrado por cuatro magistrados representantes de cada uno de los países miembros. Tiene poder judicial sobre el Acuerdo de Cartagena, sus protocolos adicionales, su propios acuerdo constitutivos, las deci- siones del Consejo de Ministros y de la Comisión. En la actualidad es el órganos integracionista por excelencia, toda vez que al ser el intérprete de la ley, puede actuar contrariamente a los intereses de los diversos gobiernos nacionales de los Estados miembros.

Sus funciones principales son:

- Controla la legalidad de las normas comunitarias, mediante la acción de nulidad

- Interpreta las normas del ordenamiento jurídico andino, velando por la aplicación uniforme en el territorio de su jurisdicción

- Dirime las controversias: ante el Tribunal pueden acudir personas naturales o jurídicas cuando crean ser afectados en sus derechos e intereses legítimos

- Conoce del recurso por "omisión" o "inactividad" cuando algún órgano o institución del SAI deja de cumplir con sus obligaciones

- Tiene función arbitral

- Tiene jurisdicción laboral.

\section{Consejo Consultivo Empresarial}

Es un órgano consultivo empresarial, creado en la búsqueda de "una mayor participación del sector empresarial en la construcción del proceso de integración tendiente a conformar el mercado común" (Comisión de la Comunidad Andina de Naciones, 1998).

Está integrado por cuatro delegados elegidos entre los directivos más importantes de organizaciones empresariales representativas de los Estados parte. Su función principal es emitir conceptos ante el Consejo de Ministros Exteriores, ante la Comisión Andina y ante la Secretaría General, a peti- 
ción de estas o de oficio, sobre temas de su interés y competencia. Pueden ser convocados a las reuniones de los grupos de trabajo y de expertos gubernamentales, vinculados a la elaboración de proyectos de decisión y pueden participar en las reuniones de la Comisión, con derecho a voz.

\section{Consejo Consultivo Laboral}

Es un órgano consultivo del SIA, creado en la búsqueda de una mayor participación del sector laboral en el proceso de integración subregional (Comisión de la Comunidad Andina de Naciones, 1998 y 2000)

Está integrado por cuatro delegados de las organizaciones laborales más representativas de los países miembros. Su función principal es emitir concepto ante el Consejo de Ministros de Relaciones Exteriores, ante la Comisión Andina y ante la Secretaría General, a petición de estas o de oficio, sobre temas de su interés y competencia. Al igual que el Consejo Consultivo empresarial, puede ser convocado a las reuniones de los grupos de trabajo y de expertos gubernamentales, vinculados a la elaboración de proyectos de decisión y puede participar en las reuniones de la Comisión, con derecho a voz.

\section{Consejo Consultivo de los Puebles Indígenas}

Es un órgano consultivo del SIA, creado en la búsqueda de una mayor participación de las comunidades indígenas (Comisión de la Comunidad Andina de Naciones, 2007).

Está integrado por un representante y un suplente de las organizaciones indígenas más importantes de cada uno de los países miembros, además de un representante, en calidad de observador, del Fondo para el Desarrollo de los Pueblos Indígenas de América Latina y del Caribe, Coordinadora de las Organizaciones Indígenas de la Cuenca Amazónica (COICA), Coordinadora Andina de las Organizaciones Indígenas (CAOI) y Enlace Continental de Mujeres Indígenas de Suramérica.

Su función principal es emitir conceptos ante el Consejo de Ministros de Relaciones Exteriores, la Comisión Andina y la Secretaría General, a petición de estas o de oficio, además de compartir y difundir experiencias, fortaleciendo de tal suerte los vínculos de cooperación entre las organizaciones indígenas, los gobiernos y la sociedad civil.

\section{Corporación Andina de Fomento (CaF)}

Órgano financiero, que actualmente constituye la principal fuente y movilización de recursos hacía la Comunidad Andina. Se trata de una institución financiera multilateral cuyos principales objetivos son velar por el desarrollo sostenible de los países accionistas y la integración subregional.

Su ayuda está dirigida tanto a los sectores público y privado, ofreciendo una gama de productos y servicios a los gobiernos de los países, instituciones financieras, $y$ empresas públicas y privadas.

Combina los objetivos financieros, con proyectos ambientales y de desarrollo social.

\section{Fondo Latinoamericano de Reservar (FLAR)}

Institución financiera del SIA cuyo objetivo principal es brindar apoyo a las balanzas de pagos de los países miembros, otorgando créditos a ellos mismos o a terceros.

Entre sus principales funciones se encuentran:

- Armonizar las políticas monetarias, cambiarias y financieras de los países.

- Mejorar las condiciones de inversio- 
nes de reservas internacionales efectuadas por las naciones andinas.

\section{Convenio Hipólito Unane (Comisión de la Comunidad Andina de Naciones, 1998)}

Institución del SIA cuyo objetivo principal el coordinar y apoyar los esfuerzos de los países miembros en materia de salud. En ese sentido coopera con otros órganos subregionales, regionales e internacionales.

\section{Convenio Simón Rodríguez}

Órgano del SIA, cuya principal función en fungir como un foro de debate, participación y coordinación en los temas de las áreas sociales y laborales de la CAN, especialmente en lo relativo a políticas referentes al fomento del empleo, la formación y capacitación laboral, la seguridad y salud en el trabajo, la seguridad social, las migraciones laborales.

Esta institución está constituida por los siguientes órganos: la Conferencia, que es el máximo órgano, que adopta las decisiones por consenso; las Comisiones Especializadas de Trabajo, cuya labor es de asesoría y, principalmente, la Secretaría Técnica.

\section{Universidad Simón Bolívar}

Institución del SiA cuyos objetivos principales son la investigación, la enseñanza, la formación posuniversitaria, la prestación de servicios y el fomento de la cooperación entre las diversas universidades de la subregión.

\subsection{Aspectos relevantes de la organización de la CAN}

Ante el fuerte impulso nacionalista que se dio a partir de 1979 en los países de la subregión, se optó por exigir la creación de instituciones que no debilitaran el poder de soberanía de los Estados parte y de dirección y control de cada uno de sus gobiernos. Se introducen así cláusulas de renuncia al Acuerdo (1988), a la vez que se lleva a cabo un progresivo debilitamiento de la Junta, quien pierde iniciativa única legislativa y la traslada y comparte con los Estados miembros. Resulta ser con el tiempo un órgano más ejecutivo y subordinado, que en sus inicios con un papel menos técnico y más político.

La Comisión siempre fue uno de los órganos más importantes de la CAN, sobre todo desde su concepción en 1969, con el paso del tiempo y principalmente con la creación del Consejo Presidencial y el Consejo de Ministros de Relaciones Exteriores, mengua su actividad al tener que someterse a las pautas y lineamientos de dichos órganos. En efecto con los consejos Presidencial y de Ministros se da paso a dos órganos que disminuyen el poder de la Comisión y de la Junta: sus lineamientos y pautas tienen un carácter de ley que deben ser obedecidos por los demás órganos.

El Consejo de Ministros dio un gran paso, respecto a la Unión Europea y otros modelos de integración subregionales como el Mercosur y el ALALC, al buscar la consolidación de una política externa común. Intento que, sin embargo, hasta el día de hoy presenta muchas dificultades, por factores como los problemas políticos internos (violencia política), inestabilidad económica de las regiones y la alta tendencia de incumplimiento de los compromisos comunitarios por parte de los Estados parte.

En la actualidad el Parlamento Andino no tiene vinculaciones funcionales con los demás órganos del SAI. Puede solicitar 
información a estos últimos, pero no están en obligación de dársela o de consultarlo para nada. El Parlamento además no tiene participación directa o indirecta en la toma de decisiones, no tiene facultad para recibir propuestas ni para proponer.

El Tribunal Andino de Justicia no ha podido alcanzar la calidad de órgano supranacional por excelencia, prevalentemente por no estar en posibilidad de llevar a cabo sus actividades netamente comunitarias. De esto es prueba el hecho de haber sobrellevado dos años de inercia desde su creación. (Coffey, 1998) Otros autores aseveran que existió una especie de acuerdo tácito entre los gobiernos para no someter controversias al conocimiento del Tribunal, por no crear tensión entre las partes. En este sentido este órgano fungió de simple "elemento decorativo" (Oliveros (Consultor de la Comunidad Andina), 1993).

Los convenios sociales, por sus funciones y su carácter podían mantenerse al margen del Acuerdo, toda vez que funcionan en forma separada.

Los gobiernos de los Estados parte son los actores principales del sistema. Esto demuestra que la CAN tiene una estructura netamente intergubernamental, que no permite el desarrollo de la Comunidad.

En el seno de la CAN, como un modelo de integración económica subregional, la experiencia ha demostrado que se prefiere lo intergubernamental, en pro de la conservación de una soberanía mal entendida de los Estados parte, a la supranacionalidad como rasgo típico de la vida comunitaria.

(...) entonces es bastante evidente el hecho de que las instituciones de la CAN no han contribuido a crear ese espíritu comunita- rio tan necesario para impulsar la integración (Bustamante, 2004).

Los anteriores aspectos ponen de manifiesto la poca conciliación en materia de intereses entre las élites nacionales de cada Estado y entre los Estados mismos.

\section{Problemáticas de la CAN}

La Comunidad Andina de Naciones es uno de los organismos supranacionales de integración regional económica más antiguos del continente, que por la duración que ha tenido y la conservación casi constante de sus miembros (de cinco países originales quedan cuatro, después de la salida de Venezuela) se podría decir que ha tenido éxito.

Sin embargo, en la realidad, qué significa algo más que durabilidad y constancia de sus miembros, el proceso que a lo largo de estos años ha llevado a cabo la CAN, tanto funcional como estructuralmente, no ha estado exento de problemas y dificultades, que en últimas obstaculizan el alcance de los fines y objetivos propuestos en común por los Estados parte.

A continuación se intentará hacer un análisis explicativo y descriptivo de las mayores problemáticas que amenazan la estabilidad de la CAN, tanto desde el ámbito de las instituciones y órganos que la componen, como desde el punto de vista de su funcionalidad y la eficacia en la producción de los resultados propuestos.

En este sentido la problemática recae en las dificultades que han significado para los miembros de la CAN llevar a cabo con éxito las acciones en conjunto, que en últimas, es una de las premisas principales de un proceso de integración regional. Más aún, si tenemos 
en cuenta que la Comunidad Andina desde sus inicios fue concebida como el medio idóneo para lograr la creación de un mercado subregional que permitiera la superación económica conjunta de los países miembros, de menor desarrollo relativo.

Dichas dificultades se manifiestan principalmente en el constante e histórico incumplimiento o aplazamiento por parte de los Estados de los compromisos adquiridos en el tiempo, como ha sucedido principalmente en la conformación definitiva de la CAN como bloque comercial, lo que ha determinado en mayor medida el estancamiento de la Comunidad. Igual situación ha ocurrido con el aún incompleto proceso del establecimiento del arancel externo común, y del programa de liberación económica y comercial por parte de los países. Prueba de esta situación reside en la expedición misma de los Protocolos de Lima y de Quito, para la ampliación de los plazos para la realización del programa de liberación y del arancel externo común, en el primero, y para el otorgamiento de mayor flexibilidad en el cumplimiento de los compromisos, en el segundo, ante la crisis coyuntural de los países suramericanos sufrida en los años 1980, y que dio lugar a políticas comerciales prevalentemente proteccionistas, para proteger las economías internas (ante una enorme deuda externa).

Los problemas identificados son:

\subsection{Un problema de interés de conflicto}

La situación descrita, que es un signo de malestar en la acción conjunta de los Estados en términos de coordinación y cooperación mutuas, hoy más que nunca parece ser el resultado de una divergencia en las políticas de cada uno de los países con las de sus congéneres, las que muchas veces se confunden con la lucha personalizada y encarnizada que mantienen sus respectivos líderes políticos en el escenario de las relaciones internacionales.

Es en este preocupante estado de rivalidad que precisamente se dio la salida de Chile en 1976, a raíz de enormes desacuerdos entre el gobierno de Pinochet y el Grupo Andino. Posteriormente, y en el mismo sentido, se dio el retiro transitorio de Perú, entre los años de 1992 y 1997, de la CAN, y recientemente el de Venezuela (2006), por la insostenible tensión existente entre los gobiernos de Hugo Chávez y Álvaro Uribe.

Sin embargo, el problema del conflicto de intereses no solo se manifiesta en el campo de lo político, sino también en el económico, en que cada Estado miembro ha demostrado tener intereses en este ámbito cada vez más lejanos de la vida comunitaria, en cuanto sus políticas económicas internas siguen diversas líneas de acción y así mismo la política exterior de cada uno de ellos está tomando caminos distintos. En este contexto notamos como mientras Venezuela ha puesto su mira en los demás países de América Latina, Ecuador, Perú y, principalmente, Colombia han estado buscando consolidar sus respectivos tratados de libre comercio con Estados Unidos.

¿Y por qué? Sencillamente porque la CAN en sí misma, considerada por sus paupérrimos resultados, ya no se tiene en cuenta como un escenario estratégico para las economías de sus miembros.

\subsection{Un problema de heterogeneidad en el desarrollo económico}

Cuando se creó la CAN, antiguo Pacto Andino, en la mente de sus partidarios existía una idea de que el proceso de integración sería más fluido al que, por
La problemática recae en las dificultades que han significado paralos miembros de la CAN llevara cabo con éxito las acciones en conjunto, que en últimas, es una de las premisas principales de un proceso de integración regional. 
ejemplo, había demostrado ser la ALALC, toda vez que el nivel de desarrollo similar de todos los Estado miembros permitiría cierto estado de homogeneidad, para los países con menor desarrollo relativo puedan crecer en sus economías de manera homogénea.

Sin embargo, la realidad ha demostrado ser distinta, más heterogénea: en efecto Ecuador y Bolivia, por el menor desarrollo económico relativo frente a Colombia y Venezuela, se han visto merecedores de regímenes especiales, que han casi que degenerado en un prototipo de "free-rider", que se traducen en la mayor contribución en la adquisición de bienes colectivos y alcance de los fines por parte de solo algunos de los miembros, pero el mismo beneficio para todos. Dicha desigualdad aporta al estancamiento del proceso integracionista.

Colombia por su parte (y Venezuela antes de retirarse), han tenido que soportar casi todo el peso del proceso, lo que en últimas ha desestimulado su participación dentro de la CAN, y los ha llevado hacia otros horizontes, particularmente Estados Unidos (piénsese en el TLC).

Así, la existencia de regímenes especiales y benéficos, casi alcahuetas de la inercia de los demás en la consecución de los fines, además de la casi inexistente colaboración de Perú en los compromisos asumidos incluso por este, han llevado a hacer casi irrisoria la esperanza de la integración regional.

\subsection{Un problema de institucionalidad}

Por medio de la creación del SAI se buscaba fortalecer el ámbito institucional a la CAN, en cuanto se propiciaba una suerte de organización interna con jerarquía establecida y con división interna de trabajo, que permitiría alcanzar eficiencia y eficacia en los procesos relativos a la integración, desde la toma de decisiones, hasta su puesta en marcha, incluso su vigilancia y control.

En este contexto se busca dotar a la CAN de un sistema completo institucional que le permitiría asegurar el debido cumplimiento de sus fines por medio del control y la supervisión del proceso, mediante la coordinación entre sus órganos e instituciones de representación tanto gubernamental como supranacional.

En ese sentido nacen órganos de carácter ejecutivo (Consejo Presidencial Andino), de dirección y decisión (Consejo Andino de Ministros de Relaciones Exteriores y la Comisión de la Comunidad Andina), jurisdiccionales (Tribunal Andino de Justicia), deliberativos (Parlamento Andino) y de apoyo técnico (Secretaría General); así como instituciones que impulsan el proceso integracionista desde distintas áreas, ya sea financiera (Corporación Andina de Fomento y el Fondo Latinoamericano de Reservas), consultiva (los Consejos Consultivos Empresarial y Laboral) y de educación, salud, trabajo y seguridad social (convenios sociales).

No obstante esta aparente distribución clara de funciones, en la CAN no es tan clara. Es más, pareciera que en los órganos de decisión reposa todo el verdadero poder de gestión y control, haciendo casi irrisoria la labor de los demás órganos.

Ante el fuerte impulso nacionalista que se dio a partir de 1979 en los países de la subregión, se optó por exigir la creación de instituciones que no debilitaran el poder de soberanía de los Estados parte y 
de dirección y control de cada uno de sus gobiernos. Se introducen así cláusulas de renuncia al Acuerdo (1988), a la vez que se lleva a cabo un progresivo debilitamiento de la Junta, quien pierde iniciativa única legislativa y la traslada y comparte con los Estados miembros. Con el tiempo resulta ser un órgano más ejecutivo y subordinado que en sus inicios, con un papel menos técnico y más político.

Aunque la Comisión siempre fue uno de los órganos más importantes de la CAN, sobre todo desde su concepción en 1969, con el paso del tiempo y principalmente con la creación de los consejos Presidencial y de Ministros de Relaciones Exteriores, mengua su actividad al tener que someterse a las pautas y lineamientos de dichos órganos. En efecto, con estos dos consejos se da paso a dos órganos que disminuyen el poder de la Comisión y de la Junta: sus lineamientos y pautas tiene un carácter de ley que deben ser obedecidos por los demás órganos.

El Consejo de Ministros dio un gran paso, respecto a la Unión Europea y otros modelos de integración subregionales como el Mercosur y el ALALC, al buscar la consolidación de una política externa común. Intento que, sin embargo, hasta el día de hoy presenta muchas dificultades, por factores como los problemas políticos internos (violencia política), inestabilidad económica de las regiones y la alta tendencia de incumplimiento de los compromisos comunitarios por parte de los Estados parte.

En la actualidad el Parlamento Andino no tiene vinculaciones funcionales con los demás órganos del SAI. Puede solicitar información a estos últimos, pero no están en obligación de dársela o de consultarlo para nada. El Parlamento además no tiene participación directa o indirecta en la toma de decisiones, no tiene facultad para recibir propuestas ni para proponer.

El Tribunal Andino de Justicia no ha podido alcanzar la calidad de órgano supranacional por excelencia, prevalentemente por no estar en posibilidad de llevar a cabo sus actividades netamente comunitarias. De esto es prueba el hecho de haber sobrellevado dos años de inercia desde su creación (Coffey, 1998). Otros autores aseveran que existió una especie de acuerdo tácito entre los gobiernos para no someter controversias al conocimiento del Tribunal, por no crear tensión entre las partes. En este sentido este órgano fungió de simple "elemento decorativo" (Oliveros (Consultor de la Comunidad Andina), 1993).

Los convenios sociales, por sus funciones y su carácter podían mantenerse al margen del Acuerdo. Funcionan en forma separada.

Los gobiernos de los Estados parte son los actores principales del sistema. Esto demuestra que la CAN tiene una estructura netamente intergubernamental, que no permite el desarrollo de la comunidad.

\section{Diferencias entre los procesos de integración de la Comunidad Andina de Naciones y la Unión Europea}

A pesar de que tanto la CAN y la Unión Europea tienen un mismo objetivo integracionista, han existido marcadas diferencias entre los dos procesos, que resaltan el gran éxito del segundo de esos organismos en el alcance de sus metas frente a los por lo general paupérrimos resultados, o más bien la falta de ellos, del proceso suramericano andino.

El presente informe pretende establecer cuáles son las principales diferencias entre 
La baja calidad de vida puede responder a decisiones internas económicas de cada uno de los países, decisionesque muchas veces no están acordes con la realidad económicay social de cada país, por lo que resultan inadecuadas. los dos bloques comerciales, determinando en ese sentido las fallas o defectos que el proceso integracionista andino presenta en la actualidad.

\subsection{Asimetrías en el nivel de vida}

Para nadie es un secreto que la calidad de vida de los habitantes de los territorios que integran la Unión Europea, que en últimas son quienes gozan de las ventajas que conlleva la vida comunitaria, es mucho más alta que la calidad de vida que mantienen los habitantes de los países que integran la Comunidad Andina de Naciones. Al punto que los países europeos, en su gran mayoría han sido denominados como "Estados de bienestar".

La baja calidad de vida puede responder a decisiones internas económicas de cada uno de los países, decisiones que muchas veces no están acordes con la realidad económica y social de cada país, por lo que resultan inadecuadas. Sin embargo, en un mundo globalizado como el nuestro, en que ya no existen por no ser viables en ningún sentido las economías cerradas, lo determinante en este punto es la falla de políticas de economía y comercio exterior en el nivel comunitario, lo que resulta ser bastante paradójico si se entiende que uno de los móviles por los que se inician procesos integracionistas es aportar desarrollo a cada uno de los países que los integran, por medio de principios de ayuda y colaboración mutuas.

Dichas fallas, con relación a la Comunidad Andina, responde a factores de variada índole, especialmente las enormes y cada vez más crecientes diferencias entre los Estados parte, tanto por las asimetrías en sus economías, como por la divergencia en las políticas internas y externas, así como por los conflictos políticos entre los gobiernos y la confrontación de intereses de diversa índole. En este escenario de marcado conflicto que, además en la actualidad, ha logrado traspasar las fronteras de la Comunidad misma y está repercutiendo en las relaciones de los Estados miembros con Estados Unidos y la Unión Europea (Acuerdo de Asociación entre la CAN y la Unión Europea, 2007), los objetivos propuestos con la integración no solo no se pueden alcanzar, sino que pueden desestabilizar las economías internas mismas.

Las asimetrías mencionadas en los distintos niveles de vida, en las paradójicas circunstancias que se encuentran la Unión Europea y la Comunidad Andina, se reflejan en la siguiente tabla:

\begin{tabular}{|l|l|}
\hline COMUNIDAD ANDINA DE NACIONES & UNIÓN EUROPEA \\
\hline 4 países miembros & 27 países miembros \\
\hline 97 millones de habitantes & 497 millones de habitantes \\
\hline PBI de US\$ 280 billones & PBI de US\$15.846 millones \\
\hline PBI per cápita de US \$2.887 anuales & PBI per cápita de US\$ 31.883 anuales. \\
\hline
\end{tabular}




\subsection{Diferencias institucionales}

Para introducir este capítulo, resulta significativo señalar la siguiente cita, sacada de una entrevista realizada por la BBC Mundo a Osvaldo Rosales, director de la División de Comercio Internacional e Integración de la Comisión Económica para América Latina y el Caribe (Cepal).

El modelo de integración europeo ha estado siempre en el subconsciente colectivo sudamericano, pero siendo realistas, las diferencias institucionales son tan marcadas que se hace difícil plantear dicho modelo como un objetivo a medio plazo.

Una primera manifestación de que eso puede ser cierto es la marcada desproporción que existe en el número de instituciones con relación a la cantidad de Estados miembros sobre los cuales aquellas adelantan el proceso integracionista, y los resultados que dicho proceso ha tenido hasta el día de hoy: mientras la Unión Europea cuanta con grandes instituciones y otros cuantos organismos vinculados, casi de carácter auxiliar, los que despliegan actividad frente a los 27 países que integran la Unión Europea, la Comunidad Andina cuenta con más de siete instituciones y otros tanto órganos, frente a cuatro países que la integran, cuyas relaciones además son endebles.

Pareciera que el control yla vinculación que tuvieran esas instituciones sobre los Estados miembros en lo que tiene que ver con la vida comunitaria fuera muy escasa en el caso de la CAN y muy fuerte en la Unión Europea, probablemente por el grado de compromiso que existe en la realización de los fines por parte de los países miembros, en una y en otra organización.
Las deficiencias existentes en la CAN, en las raíces mismas de su institucionalidad, se pueden deber a:

a. Una imposición del aspecto político sobre el económico y el cultural, "creando procesos sin viabilidad financiera, y en otras se han privilegiado los acuerdos económicos o comerciales, sin una base político-institucional estable" (BвC Mundo, 2009).

Mientras que en la Unión Europea siempre ha quedado claro que una unión económica no podía dejar de lado asuntos políticos y culturales.

b. Una copia incompleta del modelo integracionista europeo por parte de la CAN. Diversos analistas internacionales (Observatorio de las Relaciones UE-America Latina Wolf Grabendorff) han manifestado la inconveniencia de ese fenómeno, derivado del hecho de que siendo la situación del territorio europeo distinta a la del territorio suramericano, forzoso es concluir que le sirve a este último para aliviar sus males le pueda servir a aquél, pues las necesidades son diversas, el grado de desarrollo es diverso, hasta la cultura es diversa.

No se dice con lo anterior que del modelo exitoso europeo no se pueda sacar nada, solo que la simple copia no es viable, sino que se necesita un verdadero cambio institucional, de raíz, capaz de hacer frente a la situación andina.

c. Incumplimiento de la normatividad que la misma CAN se impone, por parte de los países miembros. En este sentido

Lo que Latinoamérica debe copiar del modelo de integración europeo es que debe basarse en el derecho, y ese derecho ha de ser eficaz, ha de tener legitimidad y ha de ser respetado (Observatorio de las Relaciones UE-America Latina Wolf Grabendorff). 
Por el contrario algo que ha definido a la CAN es el continuo incumplimiento de los países de las obligaciones que ellos contraen en el marco de la comunidad, lo que se ha evidenciado por las crisis internas que ha sufrido el proceso, y que se han visto reflejadas por la salida primero de Chile y, posteriormente, de Venezuela.

d. No autosacrificio por los intereses comunitarios. En efecto en el seno de la CAN, como un modelo de integración económica subregional, la experiencia ha demostrado que se prefiere lo interguber- namental, en pro de la conservación de una soberanía mal entendida de los Estados parte, a la supranacionalidad como rasgo típico de la vida comunitaria. “(...) entonces es bastante evidente el hecho de que las instituciones de la CAN no han contribuido a crear ese espíritu comunitario tan necesario para impulsar la integración” (Bustamante, 2004).

e. El débil reparto de competencias entre las instituciones de la CAN, contrario a lo que sucede con la Unión Europea como lo demuestra la siguiente tabla:
Comunidad Andina

Parlamento Andino: no tiene vinculaciones funcionales con los demás órganos del SAI. Puede solicitar información a estos últimos, pero no están en obligación de dársela o de consultarlo para nada. El Parlamento además no tiene participación directa o indirecta en la toma de decisiones, no tiene facultad para recibir propuestas ni para proponer.

Consejo Presidencial y el Consejo de Ministros se da paso a dos órganos que disminuyen el poder de la Comisión y de la Junta: sus lineamientos y pautas tienen un carácter de ley deben ser obedecidos por los demás órganos

Aunque la Comisión siempre fue uno de los órganos más importantes de la CAN, sobre todo desde su concepción en 1969, con el paso del tiempo y principalmente con la creación del Consejo Presidencial y el Consejo de Ministros de Relaciones Exteriores, mengua su actividad al tener que someterse a las pautas y lineamientos de dichos órganos.

El Tribunal Andino de Justicia no ha podido alcanzar la calidad de órgano supranacional por excelencia, prevalentemente por no estar en posibilidad de llevar a cabo sus actividades netamente comunitarias. De esto es prueba el hecho de haber sobrellevado dos años de inercia desde su creación (Coffey, 1998).
Unión Europea

Parlamento Europeo: examina y adopta la legislación de la comunidad, aprueba el presupuesto, y aprueba el nombramiento del presidente de la comisión y los miembros del colegio de comisarios, entre otras funciones.

Consejo de la Unión Europea: reúne representantes de gobiernos. Toma las decisiones de la vida comunitaria.

Comisión europea: garante de la aplicación de los tratados constitutivos de la unión y vigila la reglamentación vigente en lo comunitario como cada uno de los Estados miembros. Procedimiento de codecisión.

Tribunal de justicia: resuelve conflictos sobre interpretación de los tratados, y la legislación de la Unión. 


\section{Bibliografía}

1. Angarita, Ciro, y Coffey, Peter. (1988). Europe and the Andean Countries. A comparison of Economic Policies and Institutions. London: Edward Arn.

2. Arbuet Vignali, Heber. (2004). Las claves jurídicas de la integración en los sistemas del Mercosur y la Unión Europea, 748 p. Rubinzal-Culzoni Editores.

3. Armagnague, Juan Fernando, et ál. (2007). Estudios sobre el Mercosur, 356 p. Argentina: Cuyo.

4. Arroyo Picard, Alberto. (1997). Espejismo y realidad: el TLCAN tres años después: análisis y propuestas desde la sociedad civil, 48, 49, 58, 59, 64, 65, 194, 195. México: Red Mexicana de Acción frente al Libre Comercio.

5. Balassa, Bela. (1980). Teoría de la integración económica, 1-19 y 211-302. México: Uteha.

6. Barreix, Alberto, y Villela, Luiz. (2005). La armonización de los impuestos indirectos en la Comunidad Andina. En XVII Seminario Regional de Política Fiscal Cepal. Santiago de Chile (24-27 enero).

7. Basombrio, Ignacio. (2004). Integración andina: instituciones y derecho comunitario. En Taller internacional: integración regional-lecciones de la experiencia de la Unión Europea y la Comunidad Andina. Sao Paulo, 10-53 (20-21 de octubre).

8. Bernal Fandiño, Mariana; Garnica de la Espriella, Lorena. (2001). El Tribunal Andino de Justicia. Trabajo de grado para optar por el título de abogado, Pontificia Universidad Javeriana, Facultad de Ciencias Jurídicas. Director: Ramón Eduardo Madriñán Rivera, 126 p. Bogotá. (marzo de 2001). [Disponible en:] www.javeriana. edu.co/biblos/tesis/derecho/dere2/Tesis17.pdf (consulta: 4 noviembre de 2008).

9. BID. (1996). Las Américas: integración económica en perspectiva, 227-263. Bogotá: Departamento Nacional de Planeación de Colombia.

10. Bustamante, Ana Marleny. (2004). Desarrollo institucional de la Comunidad Andina. En Aldeamundo. Universidad de Los Andes, 8 (016), 16-23. San Cristóbal, Venezuela (noviembre-abril). [Disponible en:] redalyc.uaemex.mx (consulta: 21 noviembre de 2008).

11. Casas Gragea, Ángel María. (2001). La Comunidad Andina: 30 años en busca del desarrollo. En Revista de fomento social. España, 55 (221), 65-91 (enero-marzo). [Disponible en:] www.revistadefomentosocial.es (consulta: el 11 noviembre de 2008).

12. Comisión Económica para América Latina y el Caribe (Cepal). 1995. Desenvolvimiento de los procesos de integración en América Latina y el Caribe. (LC/R. 1527) (mayo).

13. Comisión Económica para América Latina y el Caribe (Cepal). (1992). Ensayos sobre coordinación de políticas macroeconómicas: inferencias para la integración latinoamericana, 35-63. Santiago de Chile: Naciones Unidas.

14. (Consilium) ue.eu.int (consulta: 7 y 28 de marzo de 2009).

15. Curia.europa.eu (consulta: 7 y 28 de marzo de 2009).

16. Deluca, Santiago. (2003). Unión Europea y Mercosur los efectos del derecho comunitario sobre las legislaciones nacionales, 245 p. Rubinzal-Culzoni Editores. 
17. De Zalduendo, Susana C. (1979). Tribunal Andino de Justicia. En Integración latinoamericana, Convergencia AlalC-Grupo Andino, Notas y comentarios, Año 4 (38), 32-37. Buenos Aires (agosto) [Disponible en:] www5.iadb.org/.../ integracion_latinoamericana/.../038-Notas_Comentarios_1.pdf (consulta: 4 noviembre de 2008).

18. Fuentes, Alfredo, y Villanueva, Javier. (1989). Economía mundial e integración de América Latina. Buenos Aires: Tesis.

19. Gaona Bejarano, Mauricio. (2006). La CAN frente al reto de la globalización ¿impulso o retroceso? En Jurisdictio. La Revista de Asomagister, Año 1 (1). Bogotá (segundo semestre). [Disponible en:] www.asomagister.com/Jurisdictio (consulta: 8 de noviembre de 2008).

20. Garay, Luis Jorge; Estevadeordal, Antoni. (1996). Protección, desgravación preferencial y normas de origen en las Américas. En Seminario Internacional sobre Integración Regional y Hemisférica en Perspectiva. Bogotá (noviembre).

21. Garay, Luis Jorge. (1997). Regionalismo abierto e integración en las Américas. A propósito del caso del Grupo Andino. En Lanzetta, Mónica. Agenda de largo plazo en la relación colombo-venezolana en el marco de los procesos de integración latinoamericanos y hemisféricos, 472-501 y 508-521. Bogotá: Tercer Mundo Editores, CAF, Cámara de Comercio Colombo venezolana.

22. Garay, Luis Jorge. (1979). La concepción del acuerdo de Cartagena. En Grupo Andino y proteccionismo. Contribución a un debate, 17-40 y 217-229. Bogotá: Editorial Pluma.

23. Garay, Luis Jorge. (1979). La concepción del acuerdo de Cartagena. En Grupo Andino y proteccionismo. Contribución a un debate. Bogotá: Editorial Pluma.

24. Garay, Luis Jorge. (1979). La estrategia del desarrollo implícita del Acuerdo de Cartagena: ¿una alternativa de desarrollo autónomo para los países del Grupo Andino? En Garay, Luis Jorge y Pizano, Diego. El grupo andino: objetivos, estrategias, mecanismos y avances. Bogotá: Pluma.

25. Garay, Luis Jorge. (1994). América Latina ante el reordenamiento económico internacional. Bogotá, Universidad Nacional de Colombia.

26. Geneyro, Rubén Alberto. (2007). El Mercosur por dentro. Bogotá: Ediciones Antropos.

27. Gonzales Vigil, Fernando. (2007). Logros y límites de la integración andina. En Perspectivas de la integración en América Latina y el Caribe a comienzos del siglo XXI: los 40 años de la creación del Intal. (agosto 2005, Buenos Aires). Recopilado en documento de discusión por el Centro de Investigación de la Universidad del Pacífico. [Disponible en:] http://www.up.edu.pe/ciup/ver-documentos.php (consulta: 11 de noviembre de 2008).

28. Guarnizo Ramírez, Juan Guillermo. (2007). La política regional en los esquemas de integración suramericanos CAN y Mercosur. En Papel Político Estudiantil, 3 (1), 201-230. Bogotá (enero-junio).

29. Irela. (1996). La Unión Europea y el Mercosur: ¿Hacia una nueva relación económica? Madrid: Instituto de Relaciones Europeo-Latinoamericano.

30. Junguito, Roberto. (1990). Relaciones entre la Comunidad Económica Europea y el Grupo Andino. En Integración Latinoamericana. Buenos Aires (octubrenoviembre). 
31. Katz, Raúl, y Dichter, Alexander. (1998). Línea abierta al Mercosur. En Gestión Ib, 1 (3), 28-35. Bogotá. (marzo-abril)

32. López Ochoa, Javier Mauricio. (2005). Oportunidades de negocio de la Comunidad Andina de Naciones con la Unión Europea, 34 p. Trabajo de grado para optar por el título de Administrador de Empresas. Bogotá: Pontificia Universidad Javeriana (Directora: Johanna Zitzman Betancourt).

33. Martin, Hans-Peter; Schumann, Harald. (1998). La sociedad 20:80: los líderes mundiales en marcha hacia otra civilización. En La trampa de la globalización: el ataque contra la democracia y el bienestar, 7-19. Madrid: Taurus Pensamiento (Trad. de Carlos Fortea).

34. Mezzetti, Luca. (2008). Constitución y políticas de la Unión Europea. Bogotá: Pontificia Universidad Javeriana.

35. Mengozi, Paolo (2000). Derecho comunitario y de la Unión Europea. Madrid: Tecnos.

36. Mujica San Martin, María Eugenia. (1999). Los impactos sociales y la integración: un marco teórico para la Comunidad Andina. En: Franco, Andrés y Seegers, Hubert. Globalización e integración económica: efectos sociales en Colombia, 11-31. Bogotá: Pontificia Universidad Javeriana.

37. Observatorio, de las Relaciones UE-América Latina y Fundación Friedrich Ebert. Chile.

38. Oliveros. (1993). Entrevista personal sostenida en la sede de la Junta del Acuerdo de Cartagena (consultor de la Comunidad Andina) (noviembre).

39. Pulecio, Jorge Reinel. (1997). Grupo Andino-Mercosur: ¿Una vía para la inserción creativa en el escenario internacional? En VII Encuentro de Historia y Realidad Económica y Social del Ecuador y América Latina, 141-158. Efectos de la globalización en América Latina. Cuenca: Universidad de Cuenca (noviembre).

40. Pulecio, Jorge Reinel. (1995). Del Gatt a la OMC: los cambios en el orden económico internacional. En Colombia ante la Organización Mundial de la Salud, Mincomex y Fescol, 13-29. Bogotá.

41. Quindimil López, Jorge Antonio. (2006). Instituciones y Derecho de la Comunidad Andina. Editorial Tirant Lo Blanch (diciembre).

42. Reinoso, Alan Farlie. (2000). Relaciones Comunidad Andina-Unión Europea y la zona de libre comercio del sur. Documento de Trabajo Cisepa (181). Departamento de Economía, Pontificia Universidad Católica del Perú (enero). [Disponible en:] http://www.pucp.edu.pe/economia (consulta: 11 noviembre de 2008).

43. Ricupero, Rubens. (1996). La integración y el regionalismo en las Américas. En Seminario Internacional sobre Integración Regional y Hemisférica en Perspectiva. Las Américas: integración económica en perspectiva, 83-101. Bogotá: BID, Departamento Nacional de Planeación de Colombia (noviembre).

44. Rodríguez Álvarez, Alcidez J. (2003). Las vidas paralelas de la Comunidad Andina y la Unión Europea. En Venezuela Analítica (39) (mayo). [Disponible en:] www. analítica.com (consulta: 14 abril de 2009).

45. Sanín Fonnegra, Javier. (2004). Alternativas para la Comunidad Andina frente al AlCA y a Mercosur, (S.J. 1943,ed). Bogotá: Pontificia Universidad Javeriana. 
46. Salgado, Germánico. (1970). El desarrollo y la integración de América Latina. En Sunkel, Osvaldo. Integración política y económica. Santiago: Editorial Universitaria.

47. Sierralta R., Aníbal. (2005). Mecanismos de solución de controversias en la Comunidad Andina de Naciones: desarrollo, tendencias y los desafíos del comercio internacional. En Cepal, Reino Unido. Department for International Development. Integración regional: intercambio de experiencias entre la Comunidad Andina, el Mercosur y la Comunidad Europea. Sao Paulo: Cepal. [Disponible en:] www.eclac.org (consulta: 21 de noviembre de 2008).

48. Suárez Marín, Carlos Alberto. (2007). Análisis de la institucionalidad política del Mercosur, 71 p. Trabajo de grado para optar por el título de Politólogo. Bogotá: Pontificia Universidad Javeriana. (Director Eduardo Velosa Porras).

49. Tamanes, Ramón; López, Mónica. (2002). La Unión Europea. 5ª Ed., 35-178 y 255293. Madrid: Alianza Editorial.

50. Tremolana Álvarez, Eric. (2006). Los pilares jurídicos de la Comunidad Andina: ¿Elementos decisivos para su supervivencia? En Oasis, (12), 317-346. Centro de Investigaciones y Proyectos Especiales (CIPE). Facultad de Finanzas, Gobierno y Relaciones Internacionales, Universidad Externado de Colombia (julio). [Disponible en:]. http://portal.uexternado.edu.co (consulta: 21 de noviembre de 2008).

\section{Consultas páginas web}

1. www.tribunalandino.org.ec (consulta: 4, 8 y 21 de noviembre de 2008, 7 marzo de 2009, 19 de julio, 11 de agosto y 20 de octubre de 2009).

2. www.comunidadandina.org (consulta: 20 de mayo de 2008, 2, 8 y 21 de noviembre de 2008, 7 marzo de 2009, 9 de julio, 20 de agosto y 10 de octubre 2009).

3. www.mincomercio.gov.co (consulta: 8 y 21 de noviembre de 2008, 7 marzo de 2009, 9 de julio, 20 de agosto y 10 de octubre de 2009).

4. www.cancillería.gov.co (consulta: 2, 8 y 22 de noviembre de 2008, , 7 marzo de 2009, 9 de julio, 20 de agosto y 10 de octubre de 2009).

5. www.americaeconómica.com (consulta: 8, 11 y 17 de noviembre de 2008, 7 marzo de 2009, 9 de julio, 20 de agosto y 10 de octubre de 2009).

6. www.andi.org.co (consulta: 8, 11 y 25 de noviembre de 2008, 7 marzo de 2009, 9 de julio, 20 de agosto y 10 de octubre de 2009).

7. www.cor.europa.eu (consulta: 8 y 21 de noviembre de 2008, 7 y 28 de marzo de 2009, 9 de julio, 20 de agosto y 10 de octubre de 2009).

8. www.historiasiglo20.org (consulta: 7 y 28 de marzo de 2009). 